\title{
BIOSSENSORES PLASMÔNICOS BASEADOS EM ESPALHAMENTO RAMAN INTENSIFICADO POR SUPERFÍCIE UTILIZANDO NANOBASTÕES DE OURO'
}

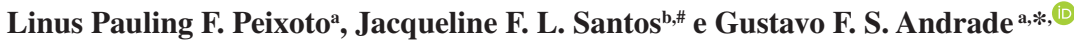 \\ a'Departamento de Química, Instituto de Ciências Exatas, Universidade Federal de Juiz de Fora, 36036-000 Juiz de Fora - MG, Brasil \\ 'Instituto de Química, Universidade Federal do Rio Grande do Sul, 91501-970 Porto Alegre - RS, Brasil
}

Recebido em 08/05/2019; aceito em 29/07/2019; publicado na web em 01/10/2019

\begin{abstract}
PLASMONIC BIOSENSORS BASED ON SURFACE-ENHANCED RAMAN SCATTERING USING GOLD NANORODS. There is still a significant need for low cost, fast and trustworthy diagnostic devices based on biosensors, which may impact positively for applications in developing countries. Localized surface plasmon resonance (LSPR) based biosensors have been taken as powerful alternative to deal with the above limitations. The local electromagnetic field enhancement caused by the LSPR in metallic nanomaterials allows the emergence of the surface enhanced Raman scattering (SERS) effect, which have recently been applied as biosensing platforms. In the present report, gold nanorods (AuNRs) were synthesized and modified with a sandwich immunoassay to detect bovine serum albumin antibody (anti-BSA). The sensitivity of the platform was evaluated by the extrinsic SERS signal from AuNRs in solution phase with added Nile blue as reporter molecule (AN-S-AuNRs), which was subsequently modified with bovine serum albumin (BSA); the assay consisted on capturing BSA modified AN-S-AuNRs by anti-BSA molecules immobilized on AuNRs on glass slides (AuNRs-chip). SERS mapping evidenced the analyte detection based on the substantial increase in the positive events with SERS signal of the reporter molecule in the presence of anti-BSA compared to the assay in the absence of the antibody. The present study may potentially guide the construction of efficient SERS immunosensors.
\end{abstract}

Keywords: gold nanorods; SERS detection; biosensors; plasmonics; Raman.

\section{INTRODUÇÃO}

Para que um material seja considerado nanométrico, deve ter uma dimensão entre 1 e $100 \mathrm{~nm} .{ }^{1}$ Entre os nanomateriais mais estudados atualmente estão as nanoestruturas de Au. Apesar de hoje ser intensamente reconhecidas como parte do campo da nanociência, as nanopartículas de Au (AuNPs) são utilizadas há séculos, estando presentes desde a coloração de vidro até aplicações biomédicas. ${ }^{2,3}$

Faraday foi o primeiro cientista a fazer um relato científico sobre a síntese de um coloide de $\mathrm{Au},{ }^{4}$ no entanto, apesar de sua relevância na ciência mundial, essa publicação serviu de referência para um número limitado de trabalhos durante muitos anos. Um desses trabalhos foi reportado por Turkevich e colaboradores em 1951, onde utilizaram citrato como agente redutor para a preparação de coloides de AuNPs, reportando inclusive a caracterização por microscopia eletrônica de varredura das nanopartículas obtidas. ${ }^{5}$ Frens aprimorou o método de Turkevich conseguindo sintetizar AuNPs esféricas com um razoável controle sobre o tamanho das nanopartículas através da variação da concentração relativa de citrato adicionada para a redução do precursor. ${ }^{6} \mathrm{Com}$ a emergência do paradigma da nanociência, ${ }^{7}$ o interesse por métodos de preparação de materiais com tamanhos dentro da escala nanométrica incentivou o surgimento de outros métodos de síntese de AuNPs. Esse esforço de pesquisa permitiu obter AuNPs com diversas formas e maior controle de tamanho. Nesse contexto se encaixam os nanobastões de $\mathrm{Au}$ (AuNRs), que foram reportados primeiramente por Murphy e colaboradores ${ }^{8}$ e posteriormente por Nikoobath e El-Sayed. ${ }^{9}$ A obtenção inicial de AuNRs foi possível pela separação entre as fases

*e-mail: gustavo.andrade@ufjf.edu.br

\#e-mail alternativo: jacqueline.ferreira@ufrgs.br

'Submetido para fazer parte do número especial em homenagem ao Prof. Hans

Stammreich por ocasião do $50^{\circ}$ aniversário do seu falecimento. de nucleação e crescimentos das nanopartículas, através de método mediado por partículas nucleadoras (seed). ${ }^{1}$

As propriedades físico-químicas particulares dessas nanoestruturas de ouro fazem com que sejam bastante interessantes. ${ }^{10} \mathrm{Uma}$ dessas propriedades é resultante da interação ressonante entre a radiação eletromagnética incidente e as estruturas metálicas com dimensão menor que o comprimento de onda da luz incidente, chamada ressonância de plasmon de superfície localizado (LSPR, do inglês localized surface plasmon resonance). Essa interação ressonante pode ser entendida como a excitação coletiva dos elétrons livres na superfície de alguns metais, como $\mathrm{Au}, \mathrm{Ag}, \mathrm{Cu}$ e Al entre outros. ${ }^{11,12} \mathrm{~A}$ ressonância ocorre na condição em que o comprimento de onda de excitação coincide com a energia de transição de um modo de oscilação coletiva dos elétrons de superfície. ${ }^{13}$

Os materiais plasmônicos que apresentam o LSPR são diversos, porém, nanoestruturas fabricadas com metais de cunhagem (Au, Ag e $\mathrm{Cu}$ ) apresentam a frequência LSPR na região do visível e infravermelho próximo, ${ }^{14}$ tornando-as mais interessantes para aplicações ópticas. Além disso, a frequência da LSPR depende fortemente do tamanho e da forma das nanoestruturas além do índice de refração do meio em que as partículas se encontram, ou seja, a variação dessas propriedades determina a posição, intensidade de absorção e largura da banda LSPR. ${ }^{15,16}$ A LSPR faz com que as AuNPs sejam estruturas muito interessantes para aplicação como biossensores, os chamados biossensores plasmônicos. ${ }^{17}$

Os biosensores utilizam o fenômeno LSPR para obter uma informação biológica pela interação com uma superfície plasmônica modificada e a transforma em um sinal analítico. Como é bem sabido, desenvolvimento de biossensores é de interesse em diversas áreas como diagnósticos clínicos, análise ambiental, biomedicina e detecção de drogas ilícitas. ${ }^{18,19}$ Normalmente são compostos por um bioreceptor (como enzimas, anticorpos, microorganismos, organelas entre outros), ${ }^{20}$ que é responsável pelo reconhecimento biológico do 
analito. O sinal biológico é então transduzido e analisado ${ }^{21}$ através da variação da posição da banda LSPR.

O uso do LSPR para biossensoriamento se deve à dependência da posição da banda LSPR com o índice de refração do ambiente em que as nanopartículas estão imersas. A sensibilidade à variação do índice de refração fez com que os sensores baseados em LSPR sejam intensamente estudados nos dias atuais. ${ }^{15,22}$ Adicionalmente, quando em ressonância, ocorre uma expressiva intensificação do campo eletromagnético local, próximo à superfície das nanopartículas plasmônicas, ${ }^{23}$ a qual permite a observação de fenômenos espectroscópicos intensificadas por superfície, ou SES (do inglês, surface enhanced spectroscopy), como o espalhamento Raman intensificado por superfície, SERS (do inglês, surface enhanced Raman scaterring) e a fluorescência intensificada por superfície, SEF (do inglês, surface enhanced fluorescence). ${ }^{24}$

O efeito SERS foi reportado pela primeira vez em 1974 por Fleischmann e colaboradores, ${ }^{25}$ que obtiveram o espectro Raman com alta relação sinal/ruído da piridina adsorvida em eletrodos de prata. Porém, foi apenas em 1977, em dois trabalhos independentes de Jeanmaire e Van Duyne e de Albrecht e Creighton, ${ }^{26,27}$ que demonstraram que a intensidade do sinal Raman na presença da superfície de prata foi muito maior do que seria esperado na ausência dela.

O efeito SERS pode ser explicado com base em dois modelos: eletromagnético ou químico. ${ }^{28} \mathrm{O}$ modelo eletromagnético se baseia na intensificação do campo eletromagnético local gerada próximo à superfície das nanopartículas metálicas pela LSPR. Por outro lado, o modelo químico apresenta uma explicação para a intensificação proveniente da excitação de transições de transferência de carga entre as nanoestruturas metálicas e as moléculas adsorvidas pela radiação excitante, que faz com que os espectros SERS possam apresentar perfil espectral muito diferente do espectro Raman não intensificado da substância de interesse. ${ }^{29}$

A amplificação do espalhamento Raman pelo efeito SERS é tipicamente da ordem de $10^{5}$ e $10^{6}$ vezes, ${ }^{30}$ sendo possível chegar a intensificações de até $10^{8}$ em regime de detecção de uma única molécula. ${ }^{31}$ Além da intensificação do efeito Raman, o efeito SERS possui diversas características vantajosas para aplicação em biossensores, como: possibilidade de detecção direta do analito; alta sensibilidade; baixa interferência de água; perfil espectral único para cada analito, uma vez que se trata de uma técnica vibracional; possibilidade de detecção de uma única molécula; entre outras. ${ }^{32}$ Todas essas características levam o SERS a ser considerado por alguns pesquisadores a mais promissora aplicação da plasmônica. ${ }^{33}$

A detecção de biomoléculas através do efeito SERS pode ser realizada principalmente por dois métodos denominados intrínseco ou extrínseco. No primeiro o analito tem seu próprio sinal SERS intensificado pelas nanoestruturas, permitindo a detecção e identificação direta do analito. Por outro lado, o segundo, utiliza uma molécula de prova que possui sinal SERS intenso e bem conhecido, associado à plataforma de detecção SERS do analito de interesse, o que resulta na detecção indireta do analito. ${ }^{34}$

Nesse âmbito, o presente trabalho teve como objetivo a construção de um biossensor plasmônico baseado no efeito SERS, utilizando um método extrínseco para a detecção do anticorpo da albumina de soro bovino (anti-BSA, do inglês bovine serum albumin antibody), para isso, utilizou-se como prova de conceito, o reconhecimento molecular pela interação antígeno-anticorpo entre BSA e anti-BSA. ${ }^{35} \mathrm{O}$ imunossensor foi construído para realizar a detecção pela configuração sanduíche. AuNRs em suspensão foram marcados com a molécula de prova azul do Nilo (AN-S-AuNRs) e modificados com BSA que foi capturado pelo anti-BSA imobilizado sobre AuNRs adsorvidos em lâminas de vidro (AuNRs-chip).

\section{PARTE EXPERIMENTAL}

\section{Materiais utilizados}

Brometo de cetiltrimetilamônio (CTAB, Fluka; 96\%); Borohidreto de Sódio $\left(\mathrm{NaBH}_{4}\right.$, Fluka; $\left.\geq 99 \%\right)$; Ácido Tetracloroáurico $\left(\mathrm{HAuCl}_{4} \cdot 3 \mathrm{H}_{2} \mathrm{O}\right.$ Sigma Aldrich; $\geq$ 99,9\%); 3-Mercaptopropril Trimetoxisilano (MPTMS, Sigma Aldrich; 95\%); Ácido Ascórbico (Sigma Aldrich; 95\%); Nitrato de Prata (Sigma Aldrich; 95\%); Ácido mercaptoundecanóico (MUA, Sigma Aldrich; 95\%); N-hidroxisuccnimida (NHS, Fluka; $\geq 97 \%$ ); N-etil-N-(3-dietilaminopropril) carbodiimida (EDC, Sigma Aldrich; $\geq 98 \%$ ); Albumina de soro bovino (Sigma Aldrich; $\geq 98 \%$ ); Anticorpo de albumina de soro bovino (Sigma Aldrich); corante azul do Nilo (AN) (Sigma Aldrich; 85\%). As soluções foram preparadas utilizando água deionizada $(\rho=18,2 \mathrm{M} \Omega \mathrm{cm})$.

\section{Equipamentos}

As medidas de espectroscopia no Ultravioleta e Visível (UV-VIS) foram realizadas utilizando um espectrofotômetro Ocean Optics 2000+ XR1 + ES com fonte excitante de 200 a $1800 \mathrm{~nm}$. Os estudos envolvendo a técnica Raman foram obtidos no espectrômetro Raman Bruker, modelo Senterra, acoplado a um microscópio óptico Olympus BX51, utilizando uma objetiva com aumento de $50 \times(\mathrm{NA}=0,50)$, permitindo a realização de medidas de mapeamento Raman, radiação excitante em $785 \mathrm{~nm}$. Os espectros SERS dos AN-S-AuNRs com radiação excitante em $785 \mathrm{~nm}$ foram realizados com 90s de exposição e potência de 50 $\mathrm{mW}$ e dos AuNRs-chip com a radiação excitante em $785 \mathrm{~nm}$ foram realizados com 4 s de tempo de exposição e potência de $25 \mathrm{~mW}$.

\section{Síntese de AuNRs}

Os AuNRs foram sintetizados utilizando o método de crescimento mediado por nanopartículas precursoras (seed), baseado no trabalho de Nikobaakth e El-Sayed. ${ }^{9}$ Resumidamente, as nanopartículas precursoras foram preparadas a partir de uma solução de CTAB $(5,00 \mathrm{~mL}, 0,20$ mol L-1) e $\mathrm{HAuCl}_{4}\left(5,00 \mathrm{~mL}, 0,0005 \mathrm{~mol} \mathrm{~L}^{-1}\right)$, à qual foi adicionada uma solução de $\mathrm{NaBH}_{4}\left(0,60 \mathrm{~mL} ; 0,01 \mathrm{~mol} \mathrm{~L}^{-1}\right)$ em banho de gelo; essa solução permaneceu sob agitação vigorosa por 2 min e depois foi deixada à temperatura ambiente por cerca de $30 \mathrm{~min}$. Para o preparo da solução de crescimento foi adicionado CTAB $\left(15,00 \mathrm{~mL}, 0,20 \mathrm{~mol} \mathrm{~L}^{-1}\right)$ a uma solução de $\mathrm{AgNO}_{3}\left(0,450 \mathrm{~mL} ; 0,004 \mathrm{~mol} \mathrm{~L}^{-1}\right)$. Posteriormente foram adicionadas uma solução de $\mathrm{HAuCl}_{4}\left(15,00 \mathrm{~mL}, 0,001 \mathrm{~mol} \mathrm{~L}^{-1}\right) \mathrm{e}$ ácido ascórbico $\left(0,210 \mathrm{~mL}, 0,0788 \mathrm{~mol} \mathrm{~L}^{-1}\right)$. Por último, foi adicionado $0,036 \mathrm{~mL}$ das nanopartículas precursoras, controlando a temperatura em $27^{\circ} \mathrm{C}$. Após cerca de 20-30 min a solução muda sua coloração de transparente para um tom avermelhado e foi mantida nessa temperatura ao menos por $3 \mathrm{~h}$. Antes da utilização dessas nanoestruturas, foi necessário retirar o excesso de $\mathrm{CTAB}$, procedimento que consiste na centrifugação dos AuNRs por 3 vezes a 10,244 rcf por 30 min e posterior redispersão em água deionizada.

\section{Construção de filmes finos de AuNRs adsorvidos sobre lâminas de vidro (AuNRs-chip)}

Como base para o imunoensaio-sanduíche foram utilizados AuNRs adsorvidos quimicamente sobre lâminas de vidro, construídos a partir do procedimento adaptado de Fan e Brolo. ${ }^{36} \mathrm{O}$ tipo de substrato obtido foi caracterizado por espectroscopia no UV-VIS e microscopia de força atômica, tendo sido aplicado como biossensor LSPR em um trabalho anterior do nosso grupo. ${ }^{37}$

As lâminas de vidro foram limpas, ${ }^{37}$ e posteriormente foram imersas em uma solução etanólica de MPTMS $10 \mathrm{mmol} \mathrm{L}^{-1}$ por $24 \mathrm{~h}$, sendo 
aquecidas a $60^{\circ} \mathrm{C}$ durante as duas primeiras horas e depois mantidas à temperatura ambiente. Em seguida, foram lavadas com etanol, para remoção do excesso de MPTMS não adsorvido, e levadas a aquecimento na temperatura de $120^{\circ} \mathrm{C}$ por $2 \mathrm{~h}$, como etapa de cura. ${ }^{37}$ Posteriormente, as lâminas foram imersas em uma suspensão de AuNRs por $24 \mathrm{~h}$; o procedimento acima consiste no primeiro ciclo de adsorção dos AuNRs.

Apenas um ciclo de adsorção não apresenta um sinal LSPR intenso o suficiente para o estudo SERS e, portanto, foram feitos mais ciclos de adsorção de AuNRs para obtenção de um número maior de nanoestruturas associadas à superfície do vidro ${ }^{37} \mathrm{e}$, consequentemente maior sinal SERS. A partir do segundo ciclo de adsorção, foi preparada uma solução de $60 \mu \mathrm{L}$ de MPTMS e $50 \mu \mathrm{L}$ de $\mathrm{HCl}$ 0,10 $\mathrm{mol} \mathrm{L}^{-1} \mathrm{em}$ $5,00 \mathrm{~mL}$ de água deionizada, que foi mantida sob agitação por $1 \mathrm{~h}$ para solubilização total do MPTMS. A lâmina com uma camada adsorvida foi imersa nessa solução por $20 \mathrm{~min}$, lavada com água deionizada e imersa na suspensão de AuNRs por $1 \mathrm{~h}$ e novamente lavada com água deionizada; essa série de procedimentos pode ser feita quantas vezes necessário, até obtenção do número de ciclos desejado. Neste trabalho os substratos foram utilizados com cinco ciclos de adsorção, apresentam intenso sinal LSPR característico dos AuNRs e satisfatório tempo de construção, posteriormente se mostraram suficientes para a obtenção de um sinal SERS da molécula de prova evidente, que são referidos aqui como AuNRs-chip.

\section{Detecção SERS de anti-BSA por imunoensaio sanduíche}

O procedimento para a detecção de biomoléculas através do SERS foi adaptado de Qian e colaboradores. ${ }^{38} \mathrm{Na}$ Figura 1 é mostrado um esquema do imunoensaio sanduíche utilizado no presente trabalho: AuNRs em suspensão foram modificados com a molécula de prova azul do Nilo (AN), responsável pelo sinal SERS a ser gerado no ensaio de detecção e com a albumina de soro bovino (BSA) (AN-S-AuNRs), enquanto que os AuNRs-chip tiveram sua superfície modificada para imobilização de BSA e posterior imobilização do analito, anti-BSA. Uma vez ocorrida a captura do analito pelo AuNRs-chip, a detecção se fez pelo sinal SERS bem característico do AN, após a adsorção seletiva do AN-S-AuNRs sobre o chip. Como branco, realizou-se todos os passos de modificações dos AuNRs, exceto para anti-BSA, permitindo assim, verificar a possibilidade de interferência de AN-S-AuNRs adsorvidos não-especificamente. Por último, o AuNRs-chip na presença ou ausência do analito foi imersa na suspensão AN-S-AuNRs durante $3 \mathrm{~h}$ e lavados com água deionizada. Após secos, foram realizados mapeamentos Raman desses substratos. Foram também obtidos espectros SERS da suspensão AN-S-AuNRs a fim de verificar a modificação com a molécula prova.

\section{Modificação da superfície da suspensão AN-S-AuNRs}

$5 \mathrm{~mL}$ de AuNRs centrifugados foram redispersos em água deionizada, mantendo sob agitação vigorosa. Em seguida, 0,500 $\mu \mathrm{L}$ de

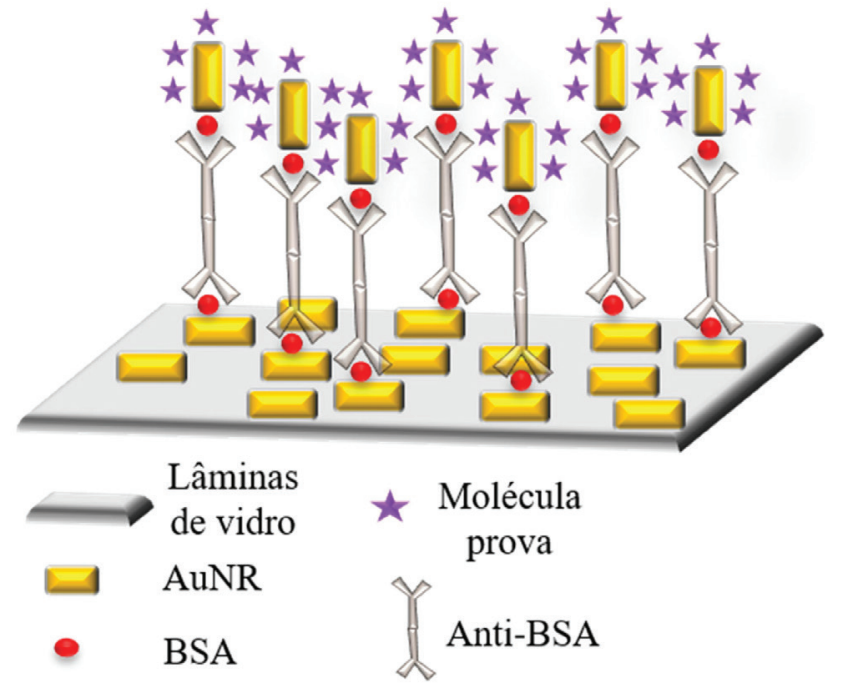

Figura 1. Esquema de detecção de anti-BSA por SERS através da configuração de imunoensaio sanduíche

AN $10 \mu \mathrm{mol} \mathrm{L} \mathrm{L}^{-1}$ foi adicionado e, após $5 \mathrm{~min}$, foram adicionados 2,0 mL de MUA 0,020 mol L-1, solubilizados em água pela adição de $\mathrm{NaOH}\left(0,20 \mathrm{~mol} \mathrm{~L}^{-1}\right)$ até que solubilize, mantendo agitação durante $24 \mathrm{~h}$. Em seguida, a suspensão foi centrifugada ( $9,641 \mathrm{rcf}$, por $20 \mathrm{~min}$ ) e redispersa em tampão salino de fosfato (PBS, do inglês phosphate buffered saline), $\mathrm{pH} 7,4$. Foram adicionados $20 \mu \mathrm{L}$ de uma solução recém-preparada, solubilizada em tampão PBS, de EDC $\left(0,050 \mathrm{~mol} \mathrm{~L}^{-1}\right) / \mathrm{NHS}\left(0,10 \mathrm{~mol} \mathrm{~L}^{-1}\right)$ a $1,0 \mathrm{~mL}$ dessa suspensão de AuNRs/AN/MUA, mantendo a mesma em agitação leve durante 25 min em vortex; em seguida, foram adicionados $50 \mu \mathrm{L}$ de BSA $1,0 \mathrm{mg} \mathrm{mL}^{-1}$ em tampão PBS, mantendo agitação leve durante $1 \mathrm{~h}$ em vortex. A suspensão modificada com BSA foi centrifugada (9,641 rcf, por $20 \mathrm{~min}$ ) e redispersa em tampão PBS para retirada do excesso de BSA (Figura 2). ${ }^{37,39}$

\section{Modificação da superfície de AuNRs-chip}

O substrato AuNRs-chip foi modificado utilizando um procedimento similar ao da suspensão AN-S-AuNRs, porém, devido ao fato de suspensões coloidais serem sujeitas a agregação, as concentrações e tempos de modificação são diferentes. O substrato AuNRs-chip foi imerso em uma solução etanólica de MUA 1,0 mmol L-1 por $72 \mathrm{~h}$. Posteriormente, foi lavado com etanol e água deionizada para retirada do excesso de MUA não adsorvido, e depois imerso em solução recém preparada de 1:1 de $\operatorname{EDC}\left(0,10 \mathrm{~mol} \mathrm{~L}^{-1}\right) / \mathrm{NHS}\left(0,10 \mathrm{~mol} \mathrm{~L}^{-1}\right)$ por 3 h e lavado com tampão PBS. Logo após, o substrato foi imerso em solução de BSA $100 \mu \mathrm{mol} \mathrm{L} \mathrm{L}^{-1}$ em PBS por $6 \mathrm{~h}$. Por último, foi lavado novamente com tampão PBS e imerso em solução de anti-BSA $1,0 \mathrm{mg} \mathrm{mL}^{-1}$ em PBS por cerca de $12 \mathrm{~h}$ (Figura 2). ${ }^{37,40}$
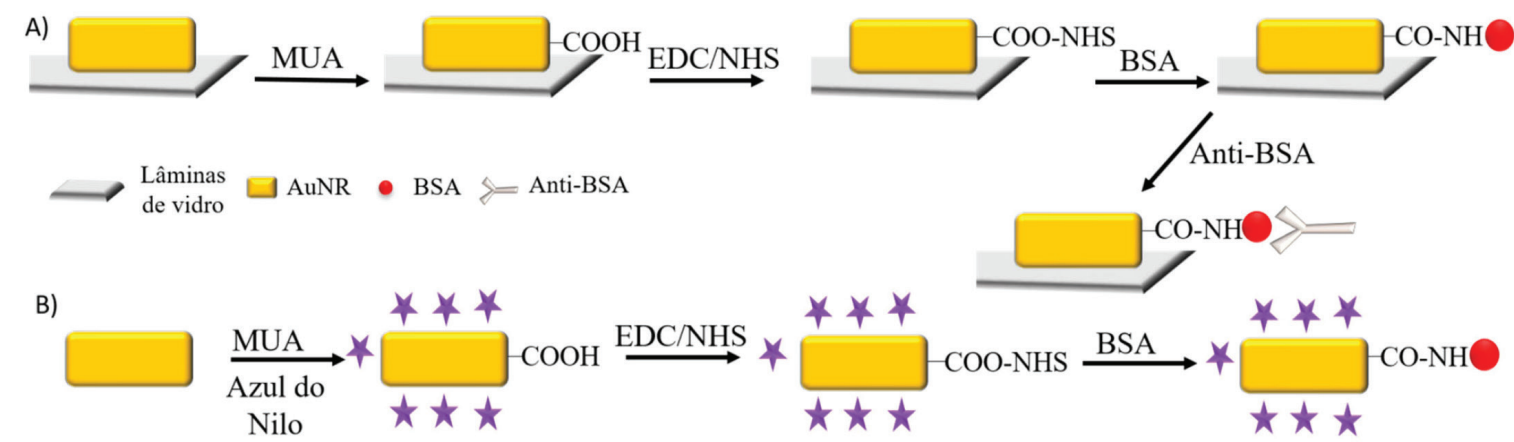

Figura 2. Esquema de modificação superficial dos AuNRs A) AuNRs-chip B) AN-S-AuNRs 



Figura 3. Espectros de UV-Vis para monitorar a modificação superficial dos substratos. A) AN-S-AuNRs B) AuNRs-chip

\section{RESULTADOS E DISCUSSÃO}

\section{Caracterização das modificações superficiais}

O primeiro passo na caracterização do biossensor SERS foi verificar a adsorção das biomoléculas na superfície dos AN-S-AuNRs e AuNRs-chip pelos métodos utilizados. A teoria de Maxwell-Garnet ${ }^{10}$ prevê que um aumento no índice de refração local faz com que o máximo da banda LSPR desloque-se para maiores comprimentos de onda. A Figura 3 apresenta os espectros no UV-VIS de ANS-AuNRs sem e com modificação por BSA e AuNRs-chip sem e com modificação por BSA e anti-BSA. É possível observar nos espectros no UV-VIS da Figura 3, um deslocamento para maiores comprimentos de onda da banda atribuída à LSPR longitudinal dos AuNRs (inicialmente em $651 \mathrm{~nm}$ para AN-S-AuNRs e $655 \mathrm{~nm}$ para AuNRs-chip) com a adição da BSA tanto para AN-S-AuNRs (Figura 3A) como para AuNRs-chip (Figura 3B). Esse deslocamento substancial na posição da banda LSPR pode ser atribuído ao grande tamanho da biomolécula BSA, que resulta em significativa mudança no índice de refração local dos AuNRs tanto para os AuNRs-chip quanto para AN-S-AuNRs. Na Figura 3B também é observado um pequeno deslocamento adicional da LSPR longitudinal do AuNRs com a modificação de anti-BSA, indicando que essa biomolécula está adsorvida na superfície dos AuNRs-chip, o que é necessário para a posterior detecção SERS. A detecção de anti-BSA por LSPR utilizando as duas configurações de AuNRs através do mesmo fenômeno de reconhecimento molecular foi realizada anteriormente. ${ }^{37}$ Percebe-se que o deslocamento causado pela presença de anti-BSA é consideravelmente menor do que para BSA, o que é atribuído à distância do anticorpo da superfície metálica devido à presença da BSA; essa distância faz com que a influência do anti-BSA sobre o índice de refração local dos AuNRs seja muito menor, afetando em menor proporção a posição da banda da LSPR.

\section{Atividade SERS dos AuNRs em suspensão}

Para realizar a detecção utilizando o SERS no método extrínseco proposto, é necessário que o substrato que contenha a molécula prova apresente sinal SERS intenso o suficiente para sua utilização. No presente trabalho, o corante AN, cuja estrutura é mostrada como inserto na Figura 4, foi selecionado devido ao seu intenso sinal SERS e espectro bem conhecido. ${ }^{41,42} \mathrm{O}$ espectro SERS da suspensão AN-SAuNRs está apresentado na Figura 4.

Observa-se no espectro da Figura 4 o sinal SERS característico do corante AN excitado em $785 \mathrm{~nm}^{42} \mathrm{O}$ espectro obtido tem alta relação sinal/ruído, o que indica que o efeito SERS é bastante intenso considerando a concentração inicial de $1,0 \times 10^{-6} \mathrm{~mol} \mathrm{~L}^{-1}$ do corante; é

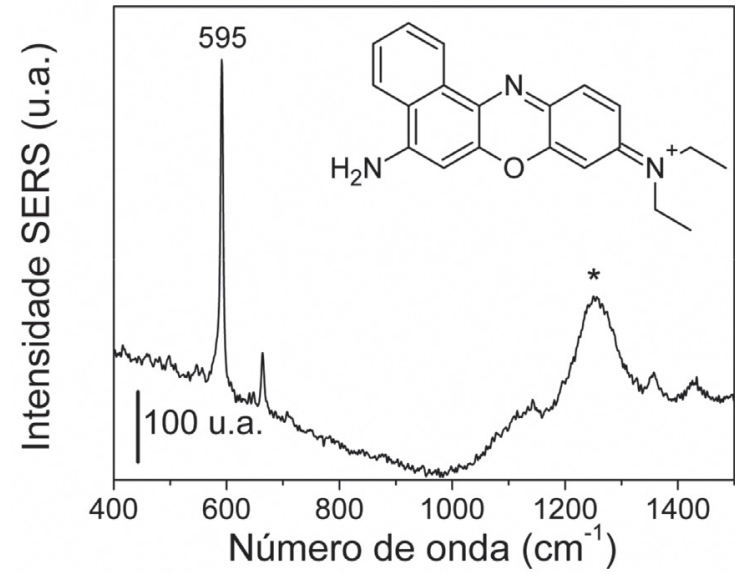

Figura 4. Espectro SERS da suspensão com a molécula AN como molécula de prova, excitado em $785 \mathrm{~nm}$. Inserto: Estrutura do corante AN. * Artefato do laser em $785 \mathrm{~nm}$

importante notar a banda mais intensa do espectro SERS em $595 \mathrm{~cm}^{-1}$, atribuída ao anel fenoxazina, ${ }^{41}$ cuja área será utilizada para obtenção dos mapeamentos químicos SERS para determinar o reconhecimento molecular nas próximas seções do presente trabalho. Tal resultado mostra que a suspensão AN-S-AuNRs possui sinal SERS satisfatório da molécula de prova, de modo que pôde ser utilizada no imunoensaio sanduíche baseado no efeito SERS. O princípio do método proposto envolve a imersão das lâminas de vidro modificadas por anti-BSA nessa suspensão, de modo que a interação entre o anti-BSA e a BSA faça com que os AN-S-AuNRs fiquem adsorvidos na lâmina de vidro, através de uma interação antígeno-anticorpo entre BSA e anti-BSA, sendo então o sinal do AN monitorado por um mapeamento químico utilizando a técnica Raman.

\section{Detecção de Anti-BSA por SERS}

Após a exposição dos AuNRs-chip ao analito anti-BSA, este substrato foi imerso na suspensão contendo AN-S-AuNRs. O sinal SERS do substrato, obtido com excitação em $785 \mathrm{~nm}$ está apresentado na Figura 5, a partir da qual é possível observar o sinal característico do corante AN. Observe que apesar de haver uma menor quantidade de moléculas espalhadoras na configuração final, ainda há uma excelente relação sinal/ruído. Este resultado confirma a presença do corante na superfície dos AuNRs-chip com o analito adsorvido na superfície.

\section{Mapeamento SERS}

A confirmação do sinal do AN nos AuNRs-chip, não indica se a adsorção é devida à interação antígeno-anticorpo entre BSA e 


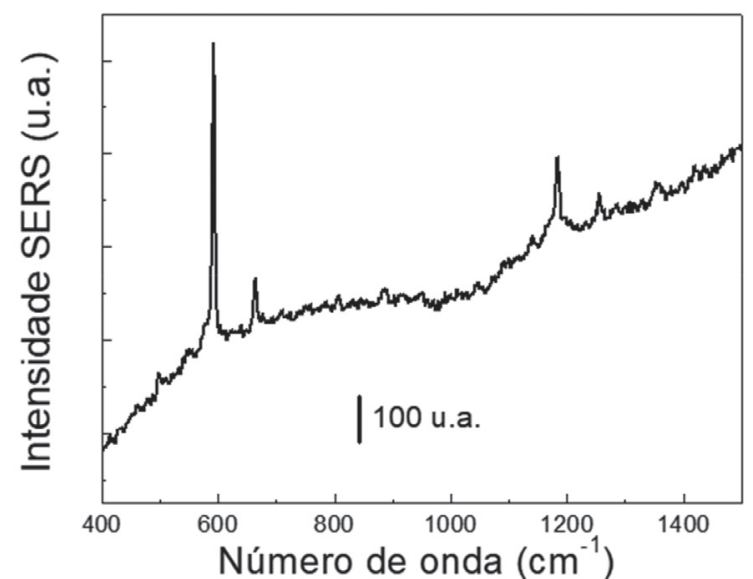

Figura 5. Espectro SERS da superfície dos AuNRs-chip após imersão na suspensão AN-S-AuNRS

anti-BSA ou apenas adsorção física dos AN-S-AuNRs, mesmo após o processo de lavagem. Sendo assim, foi realizado um experimento branco, no qual os AuNRs-chip tiveram sua superfície modificada, sem a etapa final com o anticorpo. A comparação das configurações com e sem anti-BSA através das medidas de mapeamento SERS está apresentada na Figura 6, em que é possível monitorar a intensidade e homogeneidade do sinal do corante. Os mapeamentos químicos SERS, que indicam a intensidade SERS do AN foram construídos com base na área da banda SERS em $595 \mathrm{~cm}^{-1}$ do corante (veja Figura 4), que é a banda mais intensa dos espectros e característica de corantes com anéis fenoxazínicos. ${ }^{41}$ Os mapeamentos SERS para 400 pontos são mostrados na Figura 6.

A intensidade do sinal SERS nos mapeamentos da Figura 6 é indicada pela escala de cores ao lado de cada mapeamento. A presença de anti-BSA (Figura 6B) faz com que a intensidade do sinal SERS seja maior na maioria das regiões monitoradas, como pode ser visto por uma maior predominância de cores quentes (vermelho e laranja) no mapeamento SERS. A distribuição de intensidades é heterogênea nos dois substratos, que é facilmente percebido no AuNRs-chip com anti-BSA. Parte da heterogeneidade no sinal SERS está associada à presença de regiões no AuNRs-chip que tem uma baixa densidade de AuNRs assim como regiões com uma aglomeração considerável das nanopartículas, o que resulta em uma heterogeneidade intrínseca do substrato. Para garantir que esse tipo de heterogeneidade intrínseca não interfira na determinação da qualidade do biossensor, será utilizada a proposta de procedimento de Albuquerque e colaboradores ${ }^{43}$ que envolve a construção um

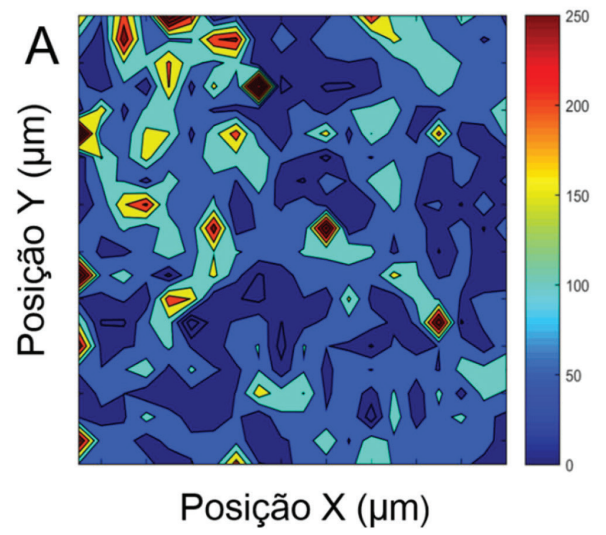

mapeamento digital da medida SERS adaptada ao presente substrato, que não envolve estudos em concentrações de moléculas individuais. No presente trabalho, os valores de intensidade SERS acima de um valor limite observados no mapeamento foram considerados como eventos positivos, e a eles foi atribuído o valor 1, e abaixo desse limite foram considerados eventos nulos, atribuídos valores 0 , resultando em um mapeamento de eventos positivos e negativos. Para obter valores-limites para separar os eventos positivos dos negativos foi utilizada a média da intensidade SERS nos mapeamentos para o experimento branco, na Figura 6A; assim foi construído um mapa digital para o experimento branco utilizando como limite a média do sinal SERS dos 400 pontos do experimento mostrado da Figura 6A, que foi de 79 contagens. O mapeamento da Figura 6B, que envolveu o analito anti-BSA, foi então reconstruído considerando que todos os pontos do mapeamento em que o sinal SERS ficou acima do limite de 79 contagens foi dado o valor 1 . Os mapeamentos SERS digitais para os dois experimentos e um gráfico de barras para número de eventos positivos são mostrados na Figura 7.

No mapeamento digital da Figura 7B é visualmente observável que o número de eventos positivos é bem maior do que o observado para a Figura 7A. Essa variação fica clara no gráfico de barras da Figura 7C, em que se tem 320 eventos positivos na presença de anti-BSA contra 166 desses eventos no experimento branco, mostrando que a presença de anti-BSA gera um sinal SERS significantemente maior do que o ensaio branco. Esse maior número de eventos positivos evidencia a detecção de anti-BSA através do imunoensaio proposto. É importante notar que essa diferenciação observada ocorre porque um grande número de regiões com sinal SERS muito baixo pode ser observado no mapeamento do experimento branco na Figura 6A. O sinal SERS na presença de anti-BSA foi tipicamente maior, apesar de apresentar alta variabilidade de intensidade; essa variabilidade pode ser atribuída à variação da geometria dos hot spots resultantes da interação específica anti-BSA/BSA da AN-S-AuNRs. Por outro lado, pode também, ser considerada uma indicação da interação específica do anti-BSA que foi imobilizado no substrato AuNRs-chip com os AN-S-AuNRs. O sinal SERS observado na ausência do anticorpo pode, finalmente, ser atribuído à adsorção física dos AN-S-AuNRs na superfície do AuNRs-chip, apesar do processo de lavagem para retirada do excesso de suspensão de AN-S-AuNRs.

\section{CONCLUSÃO}

Como prova de conceito, realizou-se a detecção da biomolécula de anti-BSA, utilizando um imunoensaio sanduíche e o método de detecção SERS extrínseco, em que o AuNRs-chip modificado com o

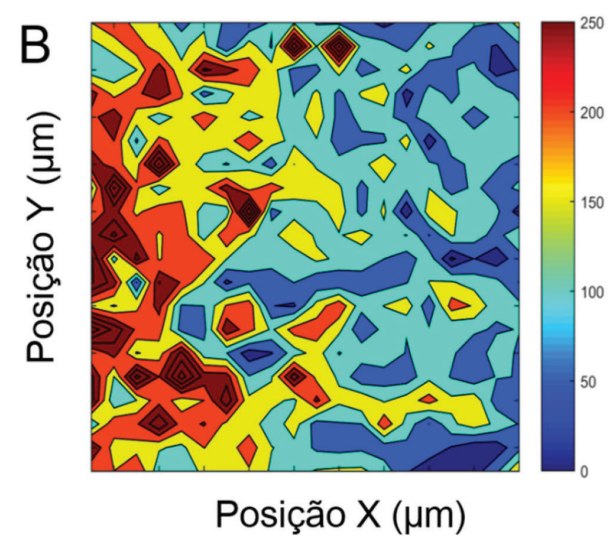

Figura 6. Mapeamento SERS de 400 pontos na superfície dos AuNRs-chip após imersão na suspensão de AN-S-AuNRS. Foi utilizada a integral da banda em $595 \mathrm{~cm}^{-1}$ do corante AN, excitado em $785 \mathrm{~nm}$. A) Imunoensaio sanduiche na ausência do analito, anti-BSA B) Imunoensaio sanduiche na presença do analito, anti-BSA. O tamanho da área mapeada no item A foi de $6200 \times 3100 \mu^{2}$ e no item B, $5720 \times 4400 \mu m^{2}$ 

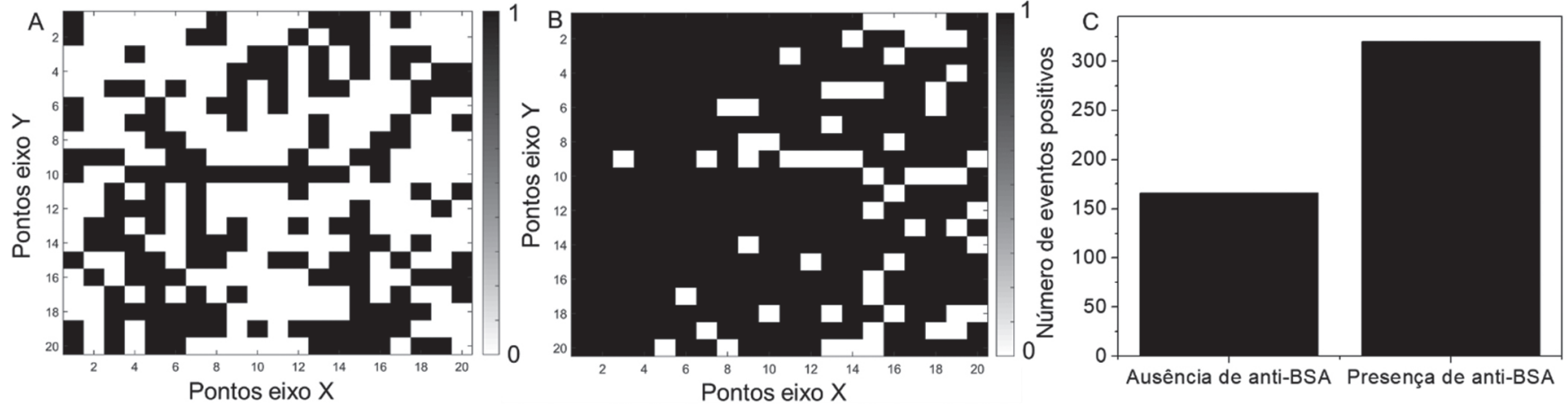

Figura 7. Tratamento de dados do mapeamento SERS, considerando a proposta de Albuquerque e colaboradores: ${ }^{43}$ A) Mapeamento SERS digital construído a partir do mapeamento do experimento branco da Figura 6A. (B) Mapeamento SERS digital construído a partir do experimento na presença de anti-BSA da Figura 6B. (C) Gráfico de barras com o número de eventos positivos em A e B. Onde os pontos em preto são eventos positivos (atribuído o valor 1)

anticorpo específico BSA serve como base, enquanto o AN-S-AuNRs modificado com BSA e com o corante azul do Nilo serve como suspensão de prova. O sinal do corante foi monitorado através de mapeamento SERS e foi observado que na presença da anti-BSA no AuNRs-chip o sinal SERS é significativamente maior comparado ao sinal do branco, evidenciado pelo maior número de eventos positivos no mapeamento SERS digital. Foi, portanto, construído um biossensor eficiente e de rápida análise para reconhecimento biomolecular de sistemas antígeno-anticorpo utilizando a técnica SERS.

\section{AGRADECIMENTOS}

Os autores agradecem à FAPEMIG, ao CNPq, à CAPES e à FAPERGS pelo suporte financeiro. LPFP agradece à CAPES pela bolsa. GFSA e JFLS agradecem ao CNPq pelas bolsas de pesquisador.

\section{REFERÊNCIAS}

1. Dreaden, E. C.; Alkilany, A. M.; Huang, X.; Murphy, C. J.; El-Sayed, M. A.; Chem. Soc. Rev. 2012, 41, 2740.

2. McNamara, K.; Tofail, S. A. M.; Adv. Phys.: X 2017, 2, 54.

3. Conde, J.; Dias, J. T.; Grazú, V.; Moros, M.; Baptista, P. V.; de la Fuente, J. M.; Front. Chem. 2014, 2, 48.

4. Faraday, M.; Philos. Trans. R. Soc. London 1857, 147, 145.

5. Turkevich, J.; Stevenson, P. C.; Hillier, J.; Discuss. Faraday Soc. 1951, 11,55 .

6. Frens, G.; Nature (London), Phys. Sci. 1973, 241, 20.

7. de Mello Donegá, C. In Nanoparticles: Workhorses of Nanoscience; de Mello Donegá, C., ed.; Springer: Berlin, Heidelberg, 2014; pp 1-12.

8. Jana, N. R.; Gearheart, L.; Murphy, C. J.; J. Phys. Chem. B 2001, 105, 4065 .

9. Nikoobakht, B.; El-Sayed, M. A.; Chem. Mater. 2003, 15, 1957.

10. Santos, J. F. L.; Santos, M. J. L.; Thesing, A.; Tavares, F.; Griep, J.; Rodrigues, M. R. F.; Quim. Nova 2016, 39, 1098.

11. Kumar, A.; Kim, S.; Nam, J.-M.; J. Am. Chem. Soc. 2016, 138, 14509.

12. Mejía-Salazar, J. R.; Oliveira, O. N.; Chem. Rev. 2018, $118,10617$.

13. Cancino, J.; Marangoni, V. S.; Zucolotto, V.; Quim. Nova 2014, 37, 521.

14. Petryayeva, E.; Krull, U. J.; Anal. Chim. Acta 2011, 706, 8.

15. Li, M.; Cushing, S. K.; Wu, N. Q.; Analyst 2015, 140, 386.

16. Hill, R. T.; Wiley Interdiscip. Rev.: Nanomed. Nanobiotechnol. 2015, 7 , 152.

17. Guo, L.; Jackman, J. A.; Yang, H.-H.; Chen, P.; Cho, N.-J.; Kim, D.-H.; Nano Today 2015, 10, 213.

18 Pérez-López, B.; Merkoçi, A.; Trends Food Sci. Technol. 2011, 22, 625.
19. Gupta, B. D.; Kant, R.; Opt. Laser Technol. 2018, 101, 144.

20. Vidotti, M.; Carvalhal, R. F.; Mendes, R. K.; Ferreira, D. C. M.; Kubota, L. T.; J. Braz. Chem. Soc. 2011, 22, 3.

21. Rai, M.; Gade, A.; Gaikwad, S.; Marcato, P. D.; Durán, N.; J. Braz. Chem. Soc. 2012, 23, 14.

22. Wang, Y. Y.; Zhou, J. H.; Li, J. H.; Small Methods 2017, 1, 1700197.

23. Lee, J.-H.; Cho, H.-Y.; Choi, H. K.; Lee, J.-Y.; Choi, J.-W.; Int. J. Mol. Sci. 2018, 19, 2021.

24. Dong, J.; Zhang, Z. L.; Zheng, H. R.; Sun, M. T.; Nanophotonics 2015, 4,472 .

25. Fleischmann, M.; Hendra, P. J.; McQuillan, A. J.; Chem. Phys. Lett. 1974, 26, 163.

26. Jeanmaire, D. L.; Vanduyne, R. P.; J. Electroanal. Chem. 1977, 84, 1.

27. Albrecht, M. G.; Creighton, J. A.; J. Am. Chem. Soc. 1977, 99, 5215.

28. Cardinal, M. F.; Vander Ende, E.; Hackler, R. A.; McAnally, M. O.; Stair, P. C.; Schatz, G. C.; Van Duyne, R. P.; Chem. Soc. Rev. 2017, 46, 3886.

29. Reguera, J.; Langer, J.; Jiménez de Aberasturi, D.; Liz-Marzán, L. M., Chem. Soc. Rev. 2017, 46, 3866.

30. Fan, M.; Andrade, G. F. S.; Brolo, A. G.; Anal. Chim. Acta 2011, 693, 7.

31. Le Ru, E. C.; Blackie, E.; Meyer, M.; Etchegoin, P. G.; J. Phys. Chem. C 2007, 111, 13794.

32. Howes, P. D.; Rana, S.; Stevens, M. M.; Chem. Soc. Rev. 2014, 43, 3835.

33. Aroca, R. F.; Phys. Chem. Chem. Phys. 2013, 15, 5355.

34. Cialla-May, D.; Zheng, X. S.; Weber, K.; Popp, J.; Chem. Soc. Rev. 2017, 46, 3945.

35. Veiseh, M.; Zareie, M. H.; Zhang, M.; Langmuir 2002, 18, 6671.

36. Fan, M.; Brolo, A. G.; Phys. Chem. Chem. Phys. 2009, 11, 7381.

37. Peixoto, L. P. F.; Santos, J. F. L.; Andrade, G. F. S.; Anal. Chim. Acta 2019, 1084, 71 .

38. Qian, X. M.; Peng, X. H.; Ansari, D. O.; Yin-Goen, Q.; Chen, G. Z.; Shin, D. M.; Yang, L.; Young, A. N.; Wang, M. D.; Nie, S. M.; Nat. Biotechnol. 2008, 26, 83-90.

39. Cao, J.; Galbraith, E. K.; Sun, T.; Grattan, K. T. V.; Sens. Actuators, B 2012, 169, 360

40. Monteiro, J. P.; Ferreira, J.; Sabat, R. G.; Rochon, P.; Santos, M. J. L.; Girotto, E. M.; Sens. Actuators, B 2012, 174, 270.

41. Brolo, A. G.; Sanderson, A. C.; Can. J. Chem. 2004, 82, 1474.

42. Rekha, C. R.; Nayar, V. U.; Gopchandran, K. G.; Journal of Science: Advanced Materials and Devices 2018, 3, 196.

43. de Albuquerque, C. D. L.; Sobral-Filho, R. G.; Poppi, R. J.; Brolo, A. G.; Anal. Chem. 2018, 90, 1248.

FAPESP contribui para custear a publicação deste artigo 